http://www.jfas.info

\title{
STUDYING THE EFFECT OF PERCEPTUAL ERRORS ON THE DECISIONS MADE BY THE INVESTORS BY EFFECTIVENESS OF INFORMATION IN TEHRAN STOCK EXCHANGE COMPANY
}

\author{
N. Yazdani1*, Y. Moshtaghi \\ Assistant Professor, Department of Business Management, Faculty of Humanities, Shahed \\ University, Tehran, Iran \\ Student of Business Management, Faculty of Humanities, Shahed University, Tehran, Iran
}

Published online: 08 August 2017

\begin{abstract}
There are many latent factors that are effective on the decisions made by the investors. The factors that the investors are not aware of their effectiveness and make investment decisions. The main purpose of the present research is to study the perceptual factors affecting on the decision making process of the investors and the effect of information on these factors. For this aim, 385 investors of Tehran Stock Exchange Company were selected as a sample through random sampling method and the required data were gathered via the questionnaire. The accuracy of the hypothesizes was tested via a structural equation model. The results obtained from the present study show that the decision making process of the investors is affected by the representative error, overconfidence error and mood state error by $19 \%$. Moreover, overconfidence error is affected by the degree of information by $95 \%$ and by the anonymity of the information by $10 \%$. The mood state error is effective on information processing time by $13 \%$ and the information processing time is effective on decision making process by $24 \%$.
\end{abstract}

Keywords: Behavioral Finance, Perceptual Error, Decision making, Investment

Author Correspondence, e-mail: n.yazdani@shahed.ac.ir

doi: http://dx.doi.org/10.4314/jfas.v9i2s.841

Journal of Fundamental and Applied Sciences is licensed under a Creative Commons Attribution-NonCommercial 4.0 International License. Libraries Resource Directory. We are listed under Research Associations category. 


\section{INTRODUCTION}

As the portfolio theory that is used in the investment analysis is based on the assumption that all the investors are risk aversion and seek to the maximizing their efficiency (Sadi et al., 2011, pp. 234). But people usually enter to a perceptual process while estimating the events and selections (Thaler, 1985, pp.201). Most of the financial and economic theories suppose that the investors act completely intellectual in decision making (Kenneth \&Nofsinger, 2008, pp.2). But study of behavioral factors as the effective factors on the investor's decision making to gain a deep insight into their decisions is necessary (Ngoc, 2014, pp.6). The investors are not intellectual in behavioral patterns unlike the neoclassic theories. In other words, the investors don't decide intellectually due to some perceptual errors. Some illogical factors same as feelings, culture, religious and ideology are the effective factors that play important role in the behavior of the people in different situations of decision making ( Rich \& Oh, 2000, pp.3-7). Some studies has been conducted in different fields of perceptual errors and the circumstances of the effect by these errors on the financial decision making of the investors in financial markets and all of them showed that the investors suffer from some errors. The perceptual errors are based on unconscious mental activities of information processing that all people possess it inherently and they make some predictive deviant from the rationality (Sadi et al., 2011, pp.235-238). The perceptual errors cause that the decision makers process the information incorrectly that leads to incorrect judgments and decisions (Arnot, 2006, pp.59). The present research aims to study the effect of perceptual errors on the decisions made by the investors and the effect of information on the perceptual errors.

\section{THEORETICAL FRAMEWORK}

\section{Behavioral Finance}

Thaler in 1999 stated that the behavioral Finance is an integration of classic finance and financial theories in psychology and decision making studies. Folerin 2000 and Fromlet in 2001, Jordan and Miller in 2001 described the behavioral Finance according to the attitude and feelings of people in the process of production and price of the market. Ritter in 2003 stated that behavioral Finance is an effort to complement of the standards for behavioral Finance theories in psychological aspect in decision making process. Along these believes, Bedi et al in 2007 described behavioral Finance knowledge as a set of financial markets models on the potential 
intervention of psychological factors in the financial investors' attitude (Bikas et al., 2013, pp.871). Behavioral Finance paradigm addresses to the circumstances of the investors' attitude and their effect on financial markets and help the investors to learn rational behavior. In fact, the conformity between the feeling and decision making method of the investor is the basis of behavioral Finance knowledge. The behavioral finance is divided into two categories of micro and macro that the micro behavioral finance addresses to the questions as if the individual investors behave rationally or if the perceptual or feeling errors of their decisions are affected (Sadi et al., 2011, 235).

\section{Perceptual Errors}

Kent Baker and John Nofsinger in 2002 provided a list of the perceptual errors that the investors encounter them and the most important of these errors are described as following (Baker \&Nofsinger, 2002, pp.101-107):

\section{Representative Error}

The human brain supposes that some items with similar specifications are equal. The representative is a kind of judgment based on Halo effect. The investors also are affected by this error regarding the good performance of the stock in the past. This effect cause that the investors seek to buy the stock of the companies or funds that had proper performance in the past. The investors rely on the proper performance of the company in the past for their performance in the future.

\section{Familiarity Bias}

People usually prefer something that is familiar with. The investors tend to buy some stocks that are familiar with them and suppose that these stocks have lower risk in compare to the unfamiliar stocks.

\section{Mood and Optimism}

People in proper mood state have more optimism judgments in compare to the people that are in bad mood. People in bad mood judge more critically.

\section{Overconfidence}

Overconfidence is closely related to mood, state and optimism. The investors have over selfconfidence on their abilities. This overconfidence is related to their ability in choosing the profitable stock. They also believe that their predictions will come true. Overconfidence lead to high risk compliance in the investment decisions. 


\section{Endowment Effect}

This kind of effect cause that people not tend to lose something that they possess. In investment issues, the investors tend to keep their investments.

\section{Status Quo Bias}

When the investors encounter with a status that they should make decision, this kind of error effect on the investor and the investor cannot take any action. Changing an investment means that the previous investment was incorrect. This status specially happens when the stock price fall. This perceptual error cause that people take no action when decreasing the stock price.

\section{Law of Small Numbers}

The investors attend to short time intervals that lead to incorrect prediction about the future. The investors think that the current trend will continue in the future.

\section{Literature Review}

In this part, the researches related in the subject of study are represented.

A research made by Zacharakis and Shepherd in 2001 on 53 investors in the business environment. These investors were selected from two entrepreneurship institutes named as Denver/Boulder and Silicon. The results obtained by this study have shown that these investors have overconfidence. The degree of this confidence will increase by increasing the information size. Moreover, if the information be anonymity, the degree of overconfidence will increase. This hypothesis stating that higher experience will lead to overconfidence was not approved. If the accessible information increase, people believe more that they make better decisions. While, increasing the information lead to increasing the complexity. Even if higher amount of information be accessible, people usually don't process all of them (Zacharakis\& Shepherd, 2001, pp.1).

A research made by Chan, Van and Vertinsky in 2003 on the effect of mood and state of mind of the businessmen on their decision making behavior in international currency exchange markets. This research has studied the effect of three states of good, indifferent and bad moods on the behavior of the businessmen. Two experimental tests were conducted, one with sample size of 66 and one with sample size of 72 . The results obtained from the research showed that the businessmen in good mood show a bad performance (actually they incurred a loss). In contrast, the businessmen in bad mood and also those in intermediate mood (not bad not good), showed a good action (actually they profited). The reason for these results could be addressed to the point 
that the businessmen in good mood make decisions with less attention, because they tend to spend less time for processing the information and making decision. They also have overconfidence and undertook high risk (Chan et al., 2003, pp.1).

A research was conducted by $\mathrm{Ke}$ and $\mathrm{Ng}$ and Wang in 2010 in American stock market on more than 3000 non-American investment funds. These funds are related to 22 countries. The results obtained by this research showed that the managers of the funds tend more to invest on the stocks of American companies that are physically active in their countries. The results of this research address to the familiarity bias among the managers of these funds (Ke et al., 2010, pp.1). A research was done bySerfas in 2011 to study the Anchoring Bias in the investments related to investment assets. Three experiments were applied in this research that showed that the perceptual error of anchoring bias will systematically deviate the judgments of the investors in taking decision. These results are inserted in both Artificially Incorporated Anchors (related to the first experiment) and in Situation Embedded Anchors (second experiment) and also in the third experiment related to the experts and experienced people (Serfas, 2011, pp.1).

A research was done in 2014 by Ngok with the aim to study the effective factors on the attitude of the investment decision makers in stock exchange of the companies in Ho Chi Minh City. The data was gathered from 188 investors in stock exchange of this city. This research defines five behavioral factors among the individual investors in stock exchange of this city including group, market, outlook, overconfidence and anchoring ability error. The group factor includes following the other investors, the market factor includes the dimensions of market price changes, information, and the outlook factor includes regret, loss aversion and mental accounting. The innovative and mental aspects are categorized into two factor of overconfidence and anchoring ability error (Ngoc,2014, pp.1).

Broihanne, Merli and Rodger in 2014 studied the role of overconfidence and perception risk in financial affairs. They interviewed with 64 experts about financial affairs. The results showed that they have overconfidence in financial affairs and also predicting the stock price. They showed that they risk that they undertake is affected positively by the overconfidence and optimism and negatively by the perception risk (Broihanne et al., 2014, pp.1).

Kaustia andRantapuska in 2015 studied the psychological effects of climate changes, season changes and daily changes on the investors' transactions in Finland. They concluded that the sun and warmth have no effect on the transaction trends, rain has a deep effect statistically and there 
are limited evidences of interventions by the emotional loads of the different seasons in tendency to purchase in contrast to selling. But the evidences showed that they have positive effect on amount of transactions. The results show that the investors do fewer transactions during the holidays and they tend to sell before holidays. The daily changes also same as climate changes and the feelings are the same as the effect of Monday (the first working day of the week). Generally, the psychological effects of daily changes and the calendar effects have no considerable effects on the trade decisions of the investors in terms of economic. However, the mood effects of these changes may be important in some of these trade decision makings among a sub category of the individual investors (Kaustia\&Rantapuska 2015, pp.1).

Wulfmeyer in 2016 studied the effect of disposition on the managers of investment funds in United States of America. They showed that the managers of investment funds are strongly affected by the disposition while validating the stocks through using different stock sizes and uncertainty factor in the market. Moreover, the disposition effect will increase uniformly by the level of systematic risk. Generally their results show that uncertainty about the stock and considerable transaction of the stocks will strength the disposition effect and the investment styles of the managers will intervene in the degree on this effect (Wulfmeyer, 2016, pp.1).

\section{RESEARCH HYPOTHESIZES}

The Hypothesizes of the present study are described as following based on the literature in the field of perceptual errors:

1. The representative error effect on the investment decisions.

2. Overconfidence error effect on the investment decisions.

And according to the researches made by Zacharakis and Shepherd, the following hypothesizes are defined based on information variable:

3. The mood state error effect on the information processing time.

4. Information processing time effect on the investment decisions.

5. The degree of information effect on overconfidence error.

6. Information anonymity effect on overconfidence error.

The definitions for the information variable are described as following: 


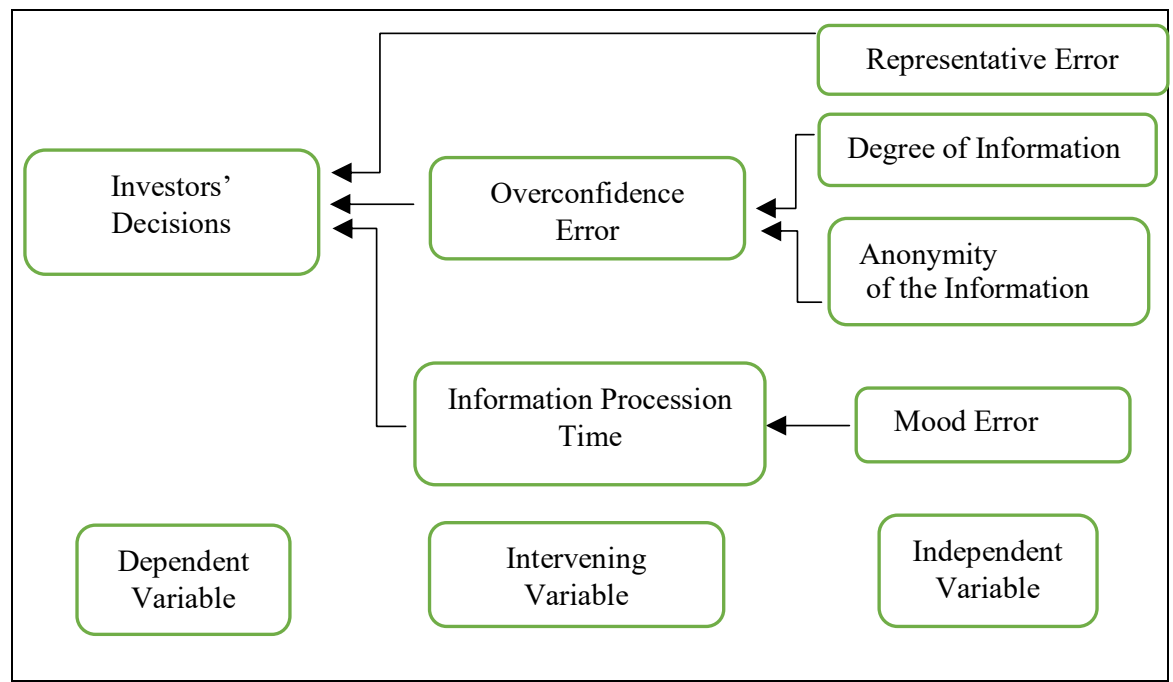

Fig.1. Conceptual Model of the Research

Information and Higher Anonymity of the Information: the information refers to the data that are sent to the receiver through a significant way (Floridi, 2005, p.2). The anonymity of the information means that the investors are not familiar with the information structure or the information related to a decision is unknown in terms of structure (Zacharakis\& Shepherd, 2001, p.5).

Information Processing: a process in which a complete analysis on the investment opportunities and information occur (Zacharakis \& Shepherd, 2001, p.6)

\section{Research Methodology}

The research methodology of the present study is applied regarding the objective of the study and descriptive-correlation regarding the nature of the study. The statistical population of the present study includes all the real entity investors of Tehran Stock Exchange. The simple random sampling method was applied equal to 385 and the data gathering was done through questionnaire. The reliability of the questionnaire of this study was estimated via Chronbach's Alpha. The comment of the experts was used to estimate the content validity and confirmatory factor analysis was used to estimate the structural validity and the structural equation model was used to measure and estimate the Hypothesizes.

\section{Research Findings}


The results obtained from the confirmatory factor analysis of exogenous latent variables.

Figure 2 shows the measurement model for exogenous latent variables in standard estimation state. As it was shown by the results, all the factor loadings are higher than $0 / 5$ that indicates the convergent validity.

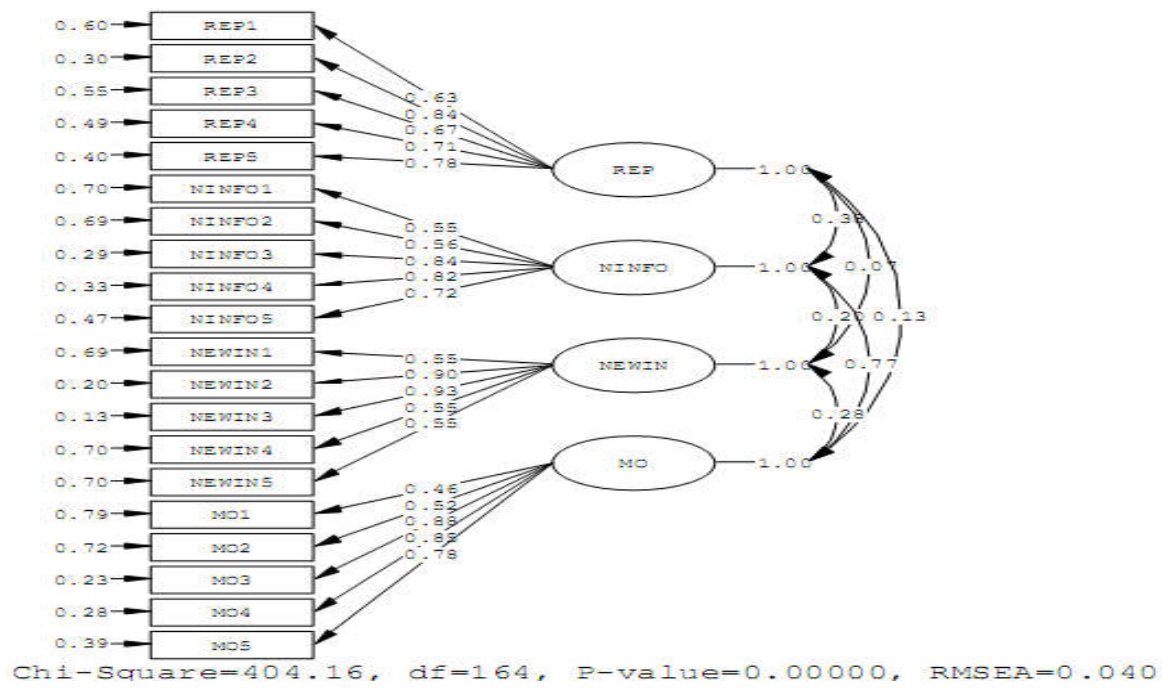

Fig.2. The Measurement Model for Exogenous Latent Variables in Standard Estimation State

Figure 3 shows the significance of the coefficients and parameters in the measurement model for exogenous latent variables in standard estimation state. The results showed that all the obtained coefficients are significant.

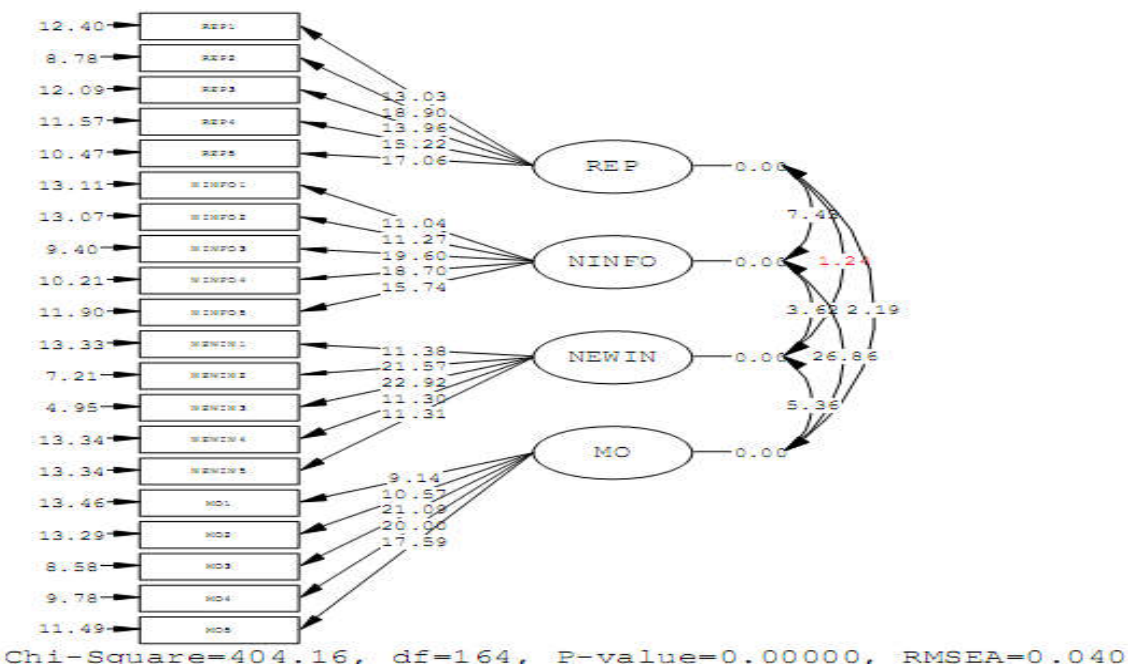

Fig.3. The Measurement Model for Exogenous Latent Variables In Significant Coefficient State 
Table 1 shows the summary of the results obtained of confirmatory factor analysis for exogenous latent variables and fitting test of the model.

Table 1. Factor Loadings, Significant Coefficients, Chronbach's Alpha and Model Fit Testing

\begin{tabular}{|c|c|c|c|c|c|c|c|c|}
\hline \multicolumn{2}{|c|}{ Mood State Error } & \multicolumn{2}{c|}{$\begin{array}{c}\text { Anonymity of } \\
\text { Information }\end{array}$} & \multicolumn{2}{c|}{$\begin{array}{c}\text { Degree of } \\
\text { Information }\end{array}$} & \multicolumn{2}{c|}{$\begin{array}{c}\text { Representative } \\
\text { Error }\end{array}$} & Questions \\
\hline $0 / 52$ & $9 / 14$ & $0 / 55$ & $11 / 38$ & $0 / 55$ & $11 / 04$ & $\begin{array}{c}0 / \\
683\end{array}$ & $13 / 03$ & 1 \\
\hline $0 / 88$ & $10 / 57$ & $0 / 90$ & $21 / 57$ & $0 / 56$ & $11 / 27$ & $0 / 84$ & $18 / 90$ & 2 \\
\hline $0 / 85$ & $21 / 09$ & $0 / 93$ & $22 / 92$ & $0 / 84$ & $19 / 60$ & $0 / 67$ & $13 / 96$ & 3 \\
\hline $0 / 78$ & $20 / 00$ & $0 / 55$ & $11 / 30$ & $0 / 82$ & $18 / 70$ & $0 / 71$ & $15 / 22$ & 4 \\
\hline $0 / 68$ & $17 / 59$ & $0 / 55$ & $11 / 31$ & $0 / 72$ & $15 / 74$ & $0 / 78$ & $17 / 06$ & 5 \\
\hline $\begin{array}{l}\text { Factor } \\
\text { Load }\end{array}$ & Statistic T & $\begin{array}{l}\text { Factor } \\
\text { Load }\end{array}$ & $\begin{array}{l}\text { Statistic } \\
\mathrm{T}\end{array}$ & $\begin{array}{l}\text { Factor } \\
\text { Load }\end{array}$ & $\begin{array}{l}\text { Statistic } \\
\mathrm{T}\end{array}$ & $\begin{array}{l}\text { Factor } \\
\text { Load }\end{array}$ & $\begin{array}{l}\text { Statistic } \\
\mathrm{T}\end{array}$ & $\begin{array}{l}\text { Confirmatory } \\
\text { Factor Analysis }\end{array}$ \\
\hline \multicolumn{3}{|c|}{$0 / 844$} & \multicolumn{2}{|c|}{$0 / 834$} & \multicolumn{2}{|c|}{$0 / 846$} & $\begin{array}{l}\text { Chronbach's } \\
\text { Alpha }\end{array}$ \\
\hline
\end{tabular}

The results obtained from the estimations (the underside of the figure) in the measurement model indicate the relative goodness of the indexes. With regards to the output of Lisrel software, the amount of $\mathrm{X}^{2}$ calculated as 404/16 that is less than 3 in proportion to the degree of freedom (164) (the ratio of chi square to degree of freedom=2/46). The amount of RMSEA equals to 0/040. The permitted limit of RMSEA equals to 0/10. AGFI, GFI and NFI indexes respectively equal to $0 / 82,0 / 85$ and 0.93 that indicate the relative fitting of the model.

The results obtained from the confirmatory factor analysis of endogenous latent variables Figure 4 shows the measurement model for endogenous latent variables in standard estimation state. According to figure 4, the factor loadings of each item and index can be observed. As the results show, all the factor loadings are higher than $0 / 5$ that shows convergent validity. 


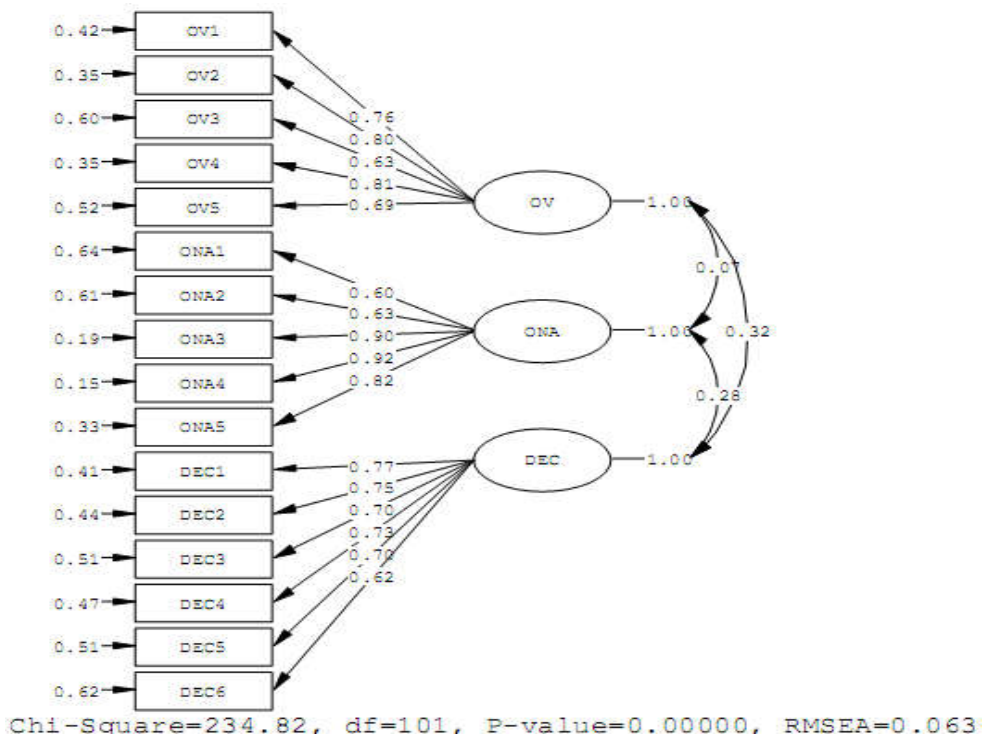

Fig.4. The Measurement Model for Endogenous Latent Variables in Standard Estimation State

Figure 5 shows the significance of the coefficients and the parameters in the measurement model for endogenous latent variables. The results showed that all the all the obtained coefficients are significant. Table 2 shows the summary of the results obtained from the confirmatory factor analysis for the endogenous latent variables.

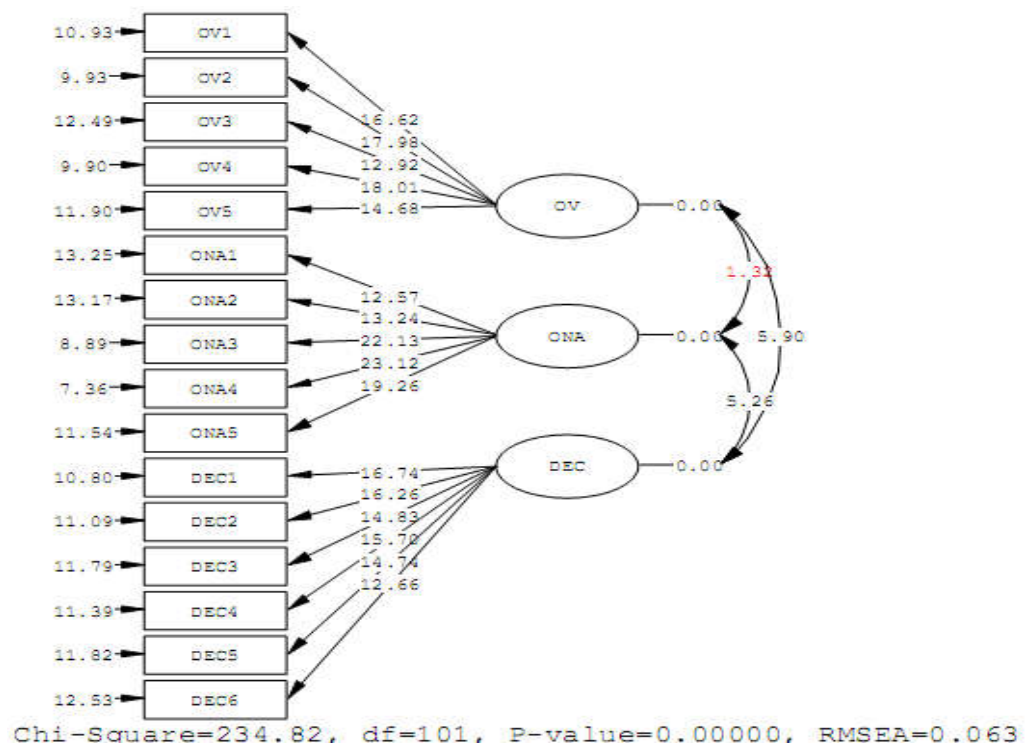

Fig.4. The Measurement Model for Endogenous Latent Variables in Significant Coefficients State 
Table 2. Factor Loadings, Significance Coefficients, Chronbach's Alpha

\begin{tabular}{|l|l|l|l|l|l|l|}
\hline \multicolumn{2}{|l|}{$\begin{array}{l}\text { Investors' } \\
\text { Decisions }\end{array}$} & \multicolumn{2}{l|}{$\begin{array}{l}\text { Information } \\
\text { Processing Time }\end{array}$} & \multicolumn{2}{l|}{$\begin{array}{l}\text { Overconfidence } \\
\text { Error }\end{array}$} & Questions \\
\hline $0 / 77$ & $16 / 74$ & $0 / 60$ & $12 / 57$ & $0 / 76$ & $16 / 62$ & 1 \\
\hline $0 / 75$ & $16 / 26$ & $0 / 63$ & $13 / 24$ & $0 / 80$ & $17 / 98$ & 2 \\
\hline $0 / 70$ & $14 / 83$ & $0 / 90$ & $22 / 13$ & $0 / 63$ & $12 / 92$ & 3 \\
\hline $0 / 73$ & $15 / 72$ & $0 / 92$ & $23 / 12$ & $0 / 81$ & $18 / 01$ & 4 \\
\hline $0 / 70$ & $14 / 74$ & $0 / 82$ & $19 / 26$ & $0 / 69$ & $14 / 68$ & 5 \\
\hline $0 / 62$ & $12 / 66$ & -- & -- & -- & -- & 6 \\
\hline $\begin{array}{l}\text { Factor } \\
\text { Loading }\end{array}$ & $\begin{array}{c}\text { Statistic } \\
\mathrm{T}\end{array}$ & $\begin{array}{l}\text { Factor } \\
\text { Loading }\end{array}$ & $\begin{array}{c}\text { Statistic } \\
\mathrm{T}\end{array}$ & $\begin{array}{l}\text { Factor } \\
\text { Loading }\end{array}$ & $\begin{array}{c}\text { Statistic } \\
\mathrm{T}\end{array}$ & $\begin{array}{l}\text { Confirmatory } \\
\text { Factor } \\
\text { Analysis }\end{array}$ \\
\hline 0.844 & & 0.834 & & 0.846 & $\begin{array}{l}\text { Chronbach's } \\
\text { Alpha }\end{array}$ \\
\hline
\end{tabular}

The results obtained from estimation (the underside of the figure) in the measurement model indicate the relative goodness of the indexes. With regards to the output of Lisrel software, the amount of $\mathrm{X}^{2}$ calculated as 234/82 that is less than 3 in proportion to the degree of freedom (101) (the ratio of chi square to degree of freedom=2/32). The amount of RMSEA equals to 0/063. The permitted limit of RMSEA equals to 0/10. AGFI, GFI and NFI indexes respectively equal to $0 / 88,0 / 91$ and $0 / 93$ that indicate the relative fitting of the model.

\section{RESEARCH HYPOTHESIZES TESTING VIA STRUCTURAL EQUATIONS MODELING}

The multi-variable analysis method was applied in the present study to confirm or reject the Hypothesizes. More professional statistical methods can be used in the multi-variable analysis same as path analysis and structural equations modeling methods. In summary, the structural equation modeling method is a method that studies all the relations between the research variables (independent, mediator, dependent) simultaneously considering the variables as latent. There are various methods to implement the structural equations model. One of the available methods is covariance-based structural equation modeling that is applied for normal variables and large sample sizes. Implementing the structural equation method with covariance-base methods require specific software that Lisrel software is the most common among them. Therefore, the Lisrel software has been used in the present study to edit the structural equation model. The null hypothesis $\mathrm{H} 0$ and $\mathrm{H} 1$ should be considered to reject or confirm the significant relations for the 
purpose of testing the Hypothesizes. The $\mathrm{H} 0$ and $\mathrm{H} 1$ are defined as following in regression relationships:

H0: there is no significant effect between two variables.

H1: there is a significant effect between two variables.

It should be noted that the rate of standard and normal error for study calculated as $0 / 05$ and the confidence level as $0 / 95$. In the level of $5 \%$ error, the critical points in the normal curve are $-1 / 96$ and 1/96. As in the normal curve, the observed error level be in the $-1 / 96$ and 1/96 limit, the H0 is accepted (there is no significant relationship between the variables) and if the observed error level be higher than the critical point, and if the observed error level be higher than critical point of $1 / 96$ and less than critical point of $-1 / 96$, the $\mathrm{H} 1$ will be accepted (there is a significant relationship between the variables). Figure 6 and 7 indicate the degree of effect of exogenous latent variables (representative error, degree of information, higher anonymity of the information and mood error) on endogenous latent variables (overconfidence error, information processing time and the investors' decisions). Table 3 shows a summary of confirmation or rejection of the relationships between the variables of the researches.

Table 3. Research Hypothesizes Testing

\begin{tabular}{|c|c|c|c|}
\hline $\begin{array}{c}\text { Rejection or } \\
\text { Confirmation of the } \\
\text { Relations }\end{array}$ & $\begin{array}{c}\text { Significance } \\
\text { (T-VALUE) }\end{array}$ & $\begin{array}{c}\text { The Degree of Effect } \\
\text { Standard ) } \\
\text { (Estimation }\end{array}$ & Hypothesizes \\
\hline Confirmed & $2 / 01$ & $0 / 11$ & (1)Hypothesis \\
\hline Confirmed & $4 / 99$ & $0 / 29$ & (2)Hypothesis \\
\hline Confirmed & $2 / 41$ & $0 / 13$ & (4)Hypothesis \\
\hline Confirmed & $4 / 25$ & $0 / 24$ & (5)Hypothesis \\
\hline Confirmed & $17 / 35$ & $0 / 95$ & (6)Hypothesis \\
\hline Confirmed & $2 / 88$ & $0 / 10$ & \\
\hline
\end{tabular}

The results showed that all the research hypothesizes were confirmed. Among the results, the degree of information on overconfidence error has the maximum effect. As the equations showed, the amount of $\mathrm{R}^{2}$ in the investor's decisions variable calculated as $0 / 19$.

The estimation results (the underside of the figure) in the measurement model indicate the relative appropriateness of the indexes. Regarding the output of Lisrel Software, the amount of $\mathrm{X}^{2}$ calculated as $923 / 71$ that is less than 3 with regard to the degree of freedom (the ratio of chi square to degree of freedom=1/58). The amount of RMSEA equals to $0 / 039$. The permitted limit 
of RMSEA equals to 0/10. AGFI, GFI and NFI indexes respectively equal to $0 / 89,0 / 91$ and 0/94 that indicate the proper fitting of the model.

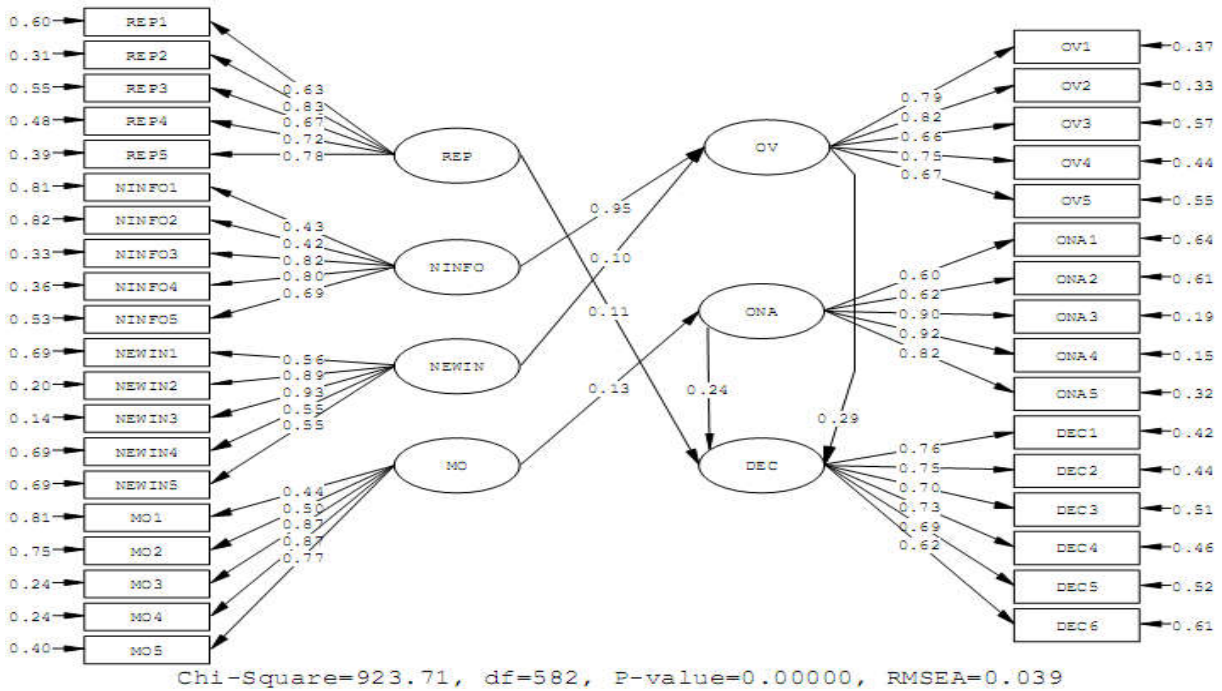

Fig.6. Structural Model (Research Hypothesis Testing) in Standard Estimation State

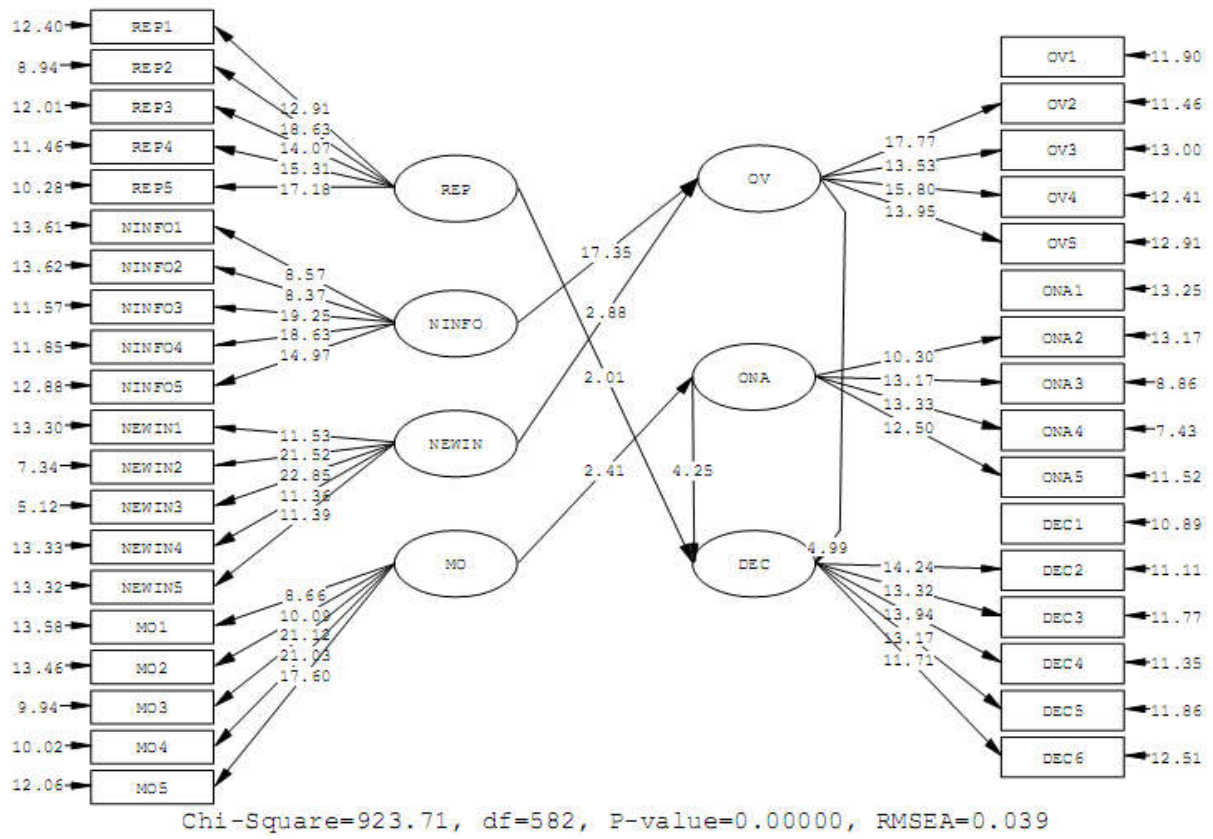

Fig.7. Structural Model (Research Hypothesis Testing) in Significance Coefficients State

\section{CONCLUSION AND SUGGESTIONS}

The effect of perceptual error on decision making of the investors is confirmed in the model obtained from the researches and literature review, a confirmation that made in the present 
research. In the first hypothesis, the representativeness effect influence the decisions made by the investors. According to the definition of representative error, the investors consider the performance of the stocks in the pas for purchasing the stocks in the present time or they buy some stocks that have their favorable specifications. In other words it could be said that the investors encounter such perceptual error by knowing this subject. In other word, the person is well aware that he/she is doing the purchasing activity based on the last purchases. Regarding the degree of effect of this error on the decisions made by the investors equal to $0 / 11$, it could be stated that this error is not in the first priority of the perceptual errors effects, but the kind of effect of this error on the decisions should be considered more seriously than its degree. It should be said about the second hypothesis that the research done by Zacharakis and Shepherd in 2001 showed that the amount of information has considerable effect on increasing the self-confidence. The effect that was calculated as $95 \%$ in the present study. In other words, information will definitely lead to higher self-confidence in Iranian investors. Therefore, the viewpoint toward these results can be segmented into two categories. View to the investors and view to the market. The individual will have higher self-confidence to choose the stock by having information. In other words, when the individual has more information about one specific stock, he/she has higher self-confidence. But in this part, the individual by having information suppose that he/she can predict the behavior of a stock and achieve more confidence to self and to that stock. The reasons for the view of Iranian investors toward the information can be addressed to the effectiveness of the market or the view to the market. The effective markets are those that provide information for everybody and nobody gain unusual profit. As it was mentioned, if the stock market be effective enough, the role of information will be equal for all. It seems that the Iranian investors perceived this important issue that the stock market is not effective and the information plays a considerable role in that. However, studying the effectiveness of a market should be investigated separately. It is worth mentioning that information gathering is not prohibited. Rather, this hypothesis states that the individual can affect the self-confidence by $95 \%$ through information gathering. Because they think that the market is not effective and they can take action more successfully through information gathering. While, people seek information under normal conditions and finally make decision through information gathering, but the gathered information doesn't create too much self-confidence, because they know that information play a same role for everybody whilst based on the Zacharakis and Shepherd, increasing the information 
value lead to some complexities and also all of the information cannot be processed completely. Zacharakis and Shepherd in 2001 stated that the anonymity of the information will effect on overconfidence, the same as the results obtained in the present study. According to the definition,anonymity ofthe information refers to the information of which the structure and kind is not known for all. The effect of this variable calculated as $10 \%$, that's mean less than the effect of the degree of information and its effect seems logical. Since, if you have some information that other people don't have, then you should have higher confidence. But in the present study, a higher effect of this variable on overconfidence was expected. The effect of this variable to such degree may be referred to the supposition of non-confidence of Iranian investors on the information that are anonym regarding the form and structure. In other words, when people achieve some information, they may benefit from them, but that information may have no considerable effect on the confidence of them due to non-confidence to that information and possibly the Iranian investors may avoid using new information and methods. In the $4^{\text {th }}$ hypothesis, the effect of overconfidence on the decisions made by the investors was approved. In other words, the results obtained in the present study were in conformity of the results in the research made by Zacharakis and Shepherd in 2001. According to the definition, the overconfidence error makes the investors gain confidence that their predictions are correct. Overconfidence leads to high risk compliance in the decisions of the investors. High risk compliance and confidence in the decision could be considered as the factors in failure in the capital market. When you affected with such conceptual error, you have overconfidence to your analysis and the received information and you cannot identify the main information flows and decide based on some statistics that may be not in conformity with your goals. The degree of effect of this error on the decisions was calculated as $29 \%$. In other words, one change unit in your self-confidence equals to 29 change unit on your decision making. Inefficiency of the market can be considered as one of the main reasons for creating such error among Iranian investors, this item will guarantee the entering into successful information flows or the presupposition that having more information will guarantee the success of a stock, although the factors in formation of a perceptual error should be studied separately. In the $5^{\text {th }}$ hypothesis, the effect of mood on information processing time duration was approved that is in conformity to the results obtained by Chan et al in 2003. The investor's mood may effect on the degree of information processing that was calculated as $13 \%$. In other words, one change unit in your mood 
will apply 13 units in the degree of information processing. But why the mood has such effect on information processing among the Iranian investors? According to the research done by Chan, people with good mood spent less time to process the information. These results may be applicable for Iranian investors. Such results may be addressed to the psychological dependency of the investors. In other words, their behavioral dependency to the mood. The importance of this effect refers to the point that people are not aware of being affected by this error. Namely, it could be called as a silent error, but clear. Because you know well that you are high spirited today (clear), but you cannot identify that there is some shortcoming in information processing time period (silent). Subsequently, they ignore the factors that contain information. In the $6^{\text {th }}$ hypothesis, the effect of information processing time period on the investment decisions was approved in conformity to the research done by Chan et al in 2003. According to the definition presented in the literature review, adapting less time for this process lead to deficiency in decision making. In other words, the investor should be able to consider all the factors in success of a stock through proper and sufficient analysis. But the investor will deprive himself of some information by decreasing the time period for information processing that may contain many values. The degree of effect of this variable on investment decisions calculated as $24 \%$. Meaning that if your information be affected by one change unit, your investment decisions will be affected by 24 change unit. The reason for change in processing time period may be addressed to the change in the mood as confirmed in $5^{\text {th }}$ hypothesis. Definitely, there are some other factors that effect on information processing time same as the ability to process the information. In other words, people have relative ability in information processing and they cannot analyze the information higher than their ability. According to the $\mathrm{R}^{2}$ estimation, the perceptual errors apply $19 \%$ effect on investment decisions generally.

\section{REFERENCES}

Arnott, D. (2006). Cognitive Biases and Decision Support Systems Development: A Design Science Approach. Information System Journal.16: 55-78

Baker, H. K., \&Nofsinger, J. R. (2002).Psychological Biases of Investors.Financial Services Review, 11: 97-116.

Bikas, E., \&Jureviciene, D., \&Dubinskas, P., \&Novickyte, L. (2013).Behavioural Finance: The Emergence and Development Trends. Social and Behavioral Sciences. 82: 870 - 876 
Broihanne, M. H.,\&Merli, M., \& Roger, P. (2014).Overconfidence, Risk Perception and the Risk-Taking Behavior of Finance Professionals,Finance Research Letters.(11)2: 64-73

Chan, F., \&Wang, D., \&Vertinsky, I. (2003). Mood in Foreign Exchange Trading: Cognitive Processes and Performance. Organizational Behavior and Human Decision Processes, 91(2): $322-338$

Floridi, L. (2005). Is Semantic Information Meaningful Data?,Philosophy and Phenomenological Research. (70)2: 351-370

Kaustia, M., \&Rantapuska, E. (2015). Does mood affect trading behavior? journal of financial markets. (29):1-26

Ke, D.,\& Ng, 1., \& Wang, Q. (2010).Home Bias in Foreign Investment Decisions.Journal of International Business Studies. 41: 960-979

Kenneth, A., \& Kim, \&Nofsinger, R. (2008).Behavioral finance in Asia,Pacific. Basin Finance Journal.16: 1-7

Ngoc, N. T. (2014). Behavior Pattern of Individual Investors in Stock Market.International Journal of Business and Management. (9)1: 1-17

Rich, R., \& Oh, C. (2000). Rationality and Use of Information in Policy Decisions: A Search for Alternatives. Science Communication. 22(2): 173-211

Sadi, S., \&GhalibafAsl, H., \&Rostami, R., \&Gholipour, A., \&Gholipour, F. (2011).Behavioral Finance: The Explanation of Investors' Personality and Perceptual Biases Effects on Financial Decisions. International Journal of Economics andFinance. (3)5:234-241

Serfas, S. (2011). The Impact of Cognitive Biases on Capital Investments: Empirical Evidence Regarding the Anchoring Heuristic. Z Plan Unternehmenssteuerung. 21: 427-446.

Thaler, R. (1985).Mental Accounting and Consumer Choice.Marketing Science. 4: 199-214 Wulfmeyer, S. (2016). Irrational Mutual Fund Managers: Explaining Differences in Their Behavior. Journal of Behavioral Finance. (17)2:99-123

Zacharakis, A. L., \&Shepherd, D. A. (2001).The Nature of Information and Overconfidence on Venture Capitalists' Decision Making.Journal of Business Venturing. 16: 311-332 


\section{How to cite this article:}

Yazdani N. Moshtaghi Y. Studying the effect of perceptual errors on the decisions made by the investors by effectiveness of information in Tehran stock exchange Company. J. Fundam. Appl. Sci., 2017, 9(2S), 1237-1254. 